\title{
Galectin-9 Produced by Intestinal Epithelial Cells Enhances Aldehyde Dehydrogenase Activity in Dendritic Cells in a PI3K- and p38-Dependent Manner
}

\author{
Sander de Kivit ${ }^{a}$ Atanaska I. Kostadinova ${ }^{a}$ JoAnn Kerperien ${ }^{a}$ \\ Veronica Ayechu Muruzabal ${ }^{a}$ Mary E. Morgan ${ }^{a}$ Leon M.J. Knippels ${ }^{a, b}$ \\ Aletta D. Kraneveld ${ }^{a} \quad$ Johan Garssen ${ }^{a}$ b Linette E.M. Willemsen ${ }^{a}$ \\ ${ }^{a}$ Division of Pharmacology, Utrecht Institute for Pharmaceutical Sciences, Utrecht University, and ${ }^{b}$ Danone Nutricia \\ Research, Utrecht, The Netherlands
}

\section{Keywords}

Dendritic cells · Intestinal epithelial cells · Galectin-9.

Toll-like receptor 9

\begin{abstract}
Intestinal epithelial cells (IEC) drive regulatory $T$ cell ( $\left.\mathrm{T}_{\text {reg }}\right)$ responses by promoting the differentiation of aldehyde dehydrogenase (ALDH)-expressing $\mathrm{CD}_{103^{+}}$dendritic cells (DC). Apical stimulation of TLR9 by CpG DNA on IEC supports galectin-9 expression by IEC, which is promoted by short-chain galacto-oligosaccharides and long-chain fructo-oligosaccharides (GF). While galectin-9 can induce the maturation of monocyte-derived DC (moDC), the contribution of galectin-9 on the induction of ALDH activity in DC is not known. To this end, DC were stimulated with galectin-9, and ALDH activity and the expression of CD103 were assessed. ALDH activity was increased by moDC exposed to galectin- 9 , while the expression of $\mathrm{CD} 103$ remained unaltered. Galectin-9 secreted by IEC apically exposed to CpG DNA and GF enhanced ALDH activity, but not CD103 expression by moDC, which was abrogated upon galectin-9 neutralization. Similar observations were found in murine GM-CSF-cultured bone marrow-derived DC (BMDC). Using Flt3L-cultured BMDC and ex vivo murine splenic $D C$, it was observed that galectin-9 only
\end{abstract}

\section{KARGER}

(C) 2017 S. Karger AG, Basel

E-Mail karger@karger.com

www.karger.com/jin enhanced ALDH activity in the presence of GM-CSF in CD103cells. The induction of ALDH activity in BMDC was dependent on p38 and PI3K signaling. These data indicate a novel role for galectin-9 in modulating innate immunity by inducing ALDH activity in DC.

(c) 2017 S. Karger AG, Basel

\section{Introduction}

Dendritic cells (DC) play an essential role in the initiation of immune responses via antigen presentation to $\mathrm{T}$ cells. Upon antigen uptake, a specific intestinal DC subset characterized by the expression of CD103 and high activity of the vitamin A-converting enzyme, aldehyde dehydrogenase (ALDH), was found to be highly effective in the induction of Foxp $3^{+}$regulatory $\mathrm{T}$ cells $\left(\mathrm{T}_{\text {reg }}\right)$ [1]. Intestinal epithelial cells (IEC) drive the differentiation of $\mathrm{CD}_{103}{ }^{+} \mathrm{DC}$ through the secretion of TSLP, retinoic acid, and TGF- $\beta$ [2]. In particular, an IRF8-dependent $\mathrm{CD}_{103}{ }^{+} \mathrm{CD} 11 \mathrm{~b}^{-}$migratory conventional DC (cDC) subset in the gut mucosa show the highest expression of

Dr. Sander de Kivit

The Netherlands Cancer Institute, Antoni van Leeuwenhoek Hospital, Plesmanlaan 121 NL-1066 CX Amsterdam (The Netherlands)

E-Mail s.d.kivit@nki.nl

Dr. Linette E.M. Willemsen

Division of Pharmacology, Utrecht Institute for Pharmaceutical Sciences Utrecht University, PO Box 80082

NL-3508 TB Utrecht (The Netherlands)

E-Mail l.e.m.willemsen@uu.nl 
ALDH and most abundantly expressed genes associated with $\mathrm{T}_{\text {reg }}$ induction in the gut mucosa $[3,4]$. While $\mathrm{CD}_{103^{+}}{ }^{\mathrm{DC}}$ can efficiently drive effector $\mathrm{T}$ cell responses or $\mathrm{T}_{\text {reg }}$ induction, $\mathrm{CD}^{-103^{-}}$intestinal DC subsets have also been found to be critical in the induction of Th1 and Th17 type effector responses in the gut $[4,5]$.

We previously identified galectin- 9 as a potential mediator released by IEC to prevent acute allergic symptoms [6]. IEC apically stimulated with CpG DNA contribute to immunological tolerance, and it was previously observed that apical TLR9 ligation on IEC enhanced galectin-9 mRNA expression and secretion by IEC in vitro $[7,8]$. The presence of a 9:1 mixture of short-chain galacto-oligosaccharides and long-chain fructo-oligosaccharides (GF) further enhanced galectin-9 mRNA expression and protein secretion by HT-29 cells induced by CpG DNA in vitro [8]. These findings were substantiated in additional in vivo studies, showing that GF in combination with $B i$ fidobacterium breve $\mathrm{M}-16 \mathrm{~V}$ may induce $\mathrm{T}_{\text {reg }}$ polarization in the gut-associated lymphoid tissue via IEC-derived galectin-9. In a murine model for food allergy, it was found that the ratio between Foxp3 and GATA-3 mRNA expression was increased in the mesenteric lymph nodes of whey-sensitized mice fed $B$. breve M-16V and GF. Furthermore, supplementation of galectin- 9 to activated human peripheral blood mononuclear cells was found to enhance the frequency of $\mathrm{T}_{\text {reg }}$ cells in vitro [6]. B. breve $\mathrm{M}$ $16 \mathrm{~V}$ may signal via TLR9 expressed by IEC, as genomic DNA of $B$. breve $\mathrm{M}-16 \mathrm{~V}$ increase IFN- $\gamma$ secretion by peripheral blood mononuclear cells (PBMC) in an epithelium-dependent manner similar to a synthetic CpG DNA oligonucleotide [8]. Other studies have shown that activation of monocyte-derived DC with galectin- 9 can result in the induction of both $\mathrm{T}_{\text {reg }}$ and Th1 type effector responses [9-13]. However, it is not known whether IECderived galectin-9 can support the differentiation of $\mathrm{CD}_{103}{ }^{+} \mathrm{DC}$ that exhibit high ALDH activity.

In this study, we assessed whether IEC-derived galectin-9 plays a role in the induction of ALDH activity by DC. We showed that galectin-9 drove ALDH activity in IL-4/GM-CSF-generated human moDC and murine GM-CSF-generated bone marrow-derived DC (GMBMDC). IEC exposed apically to GpG DNA and GF increased ALDH activity by moDC, and the neutralization of galectin-9 in IEC-conditioned medium abrogated this effect. Flt3L-generated BMDC (FL-BMDC) or ex vivo splenic cDC did not show ALDH activity upon stimulation with galectin-9. However, GM-CSF was crucial for the induction of ALDH activity by these DC as galectin-9 only increased ALDH activity in FL-BMDC or splenic
cDC in the presence of GM-CSF. ALDH activity in DC induced by galectin- 9 was found to be dependent on p38 and PI3K signaling. Our data provide evidence for a novel role of galectin-9 in the regulation of innate immunity via the induction of ALDH activity by DC.

\section{Materials and Methods}

\section{Culture of IEC Lines}

HT-29 and T84 cell cultures and transwell experiments were performed as previously described [14]. IEC were grown in 6-well transwell plates (Corning) and basolaterally exposed to recombinant human TNF- $\alpha$ and IFN- $\gamma$ (both $10 \mathrm{ng} / \mathrm{mL}$; Invitrogen) in RPMI1640 (Gibco) supplemented with 10\% heat-inactivated FCS and penicillin $(100 \mathrm{U} / \mathrm{mL}) /$ streptomycin $(100 \mu \mathrm{g} / \mathrm{mL})$. After overnight culture, the cytokines were washed away and IEC were apically exposed to $5 \mu \mathrm{M}$ TLR9 ligand (M362 CpG oligonucleotide type C; Invitrogen) in the presence or absence of $0.5 \% \mathrm{w} / \mathrm{v}$ of a 9:1 mixture of short-chain galacto-oligosaccharides (Vivinal GOS, Borculo Domo) and long-chain fructo-oligosaccharides (Raftiline $\mathrm{HP}$, Orafti) for $24 \mathrm{~h}$. Basolateral conditioned medium was collected and stored at $-20^{\circ} \mathrm{C}$.

\section{Culture of Human moDC}

PBMC were isolated as previously described [14]. CD14 ${ }^{+}$cells were isolated from PBMC by negative selection using MACS (Miltenyi Biotec) according to the manufacturer's protocol. Purity was assessed by flow cytometry and was generally 90-95\%. CD $14^{+}$cells were cultured for 7 days in RPMI1640 (Gibco) supplemented with $10 \%$ heat-inactivated FCS, penicillin $(100 \mathrm{U} / \mathrm{mL}) /$ streptomycin $(100 \mu \mathrm{g} / \mathrm{mL})$, recombinant human IL-4 and GM-CSF (30 and 15 ng/mL, respectively; Prospec). Cultures were supplemented with recombinant galectin- $9(1 \mu \mathrm{g} / \mathrm{mL}$; R\&D Systems $)$ or $50 \%$ IEC-conditioned medium, starting from the start of moDC cultures where indicated. Medium was replenished at days 2, 3, and 5 of culture.

\section{Culture of Murine BMDC}

$\mathrm{BMDC}$ were generated from wild-type $\mathrm{Balb} / \mathrm{c}$ or $\mathrm{C} 57 \mathrm{Bl} / 6$ mice as previously described (GM-CSF was obtained from PeproTech, recombinant mouse Flt3L was a kind gift from Dr. Iglesia at the Dutch Cancer Institute and was made in-house) [15]. Some BMDC cultures were exposed to inhibitors for the mitogen-activated protein kinases (MAPK) p38 (SB203580, $10 \mu \mathrm{M}), \mathrm{c}$-JUN N-terminal kinase (JNK; SP600125, $25 \mu \mathrm{M}$ ), extracellular signal-regulated kinase (ERK1/2; U0126, $10 \mu \mathrm{M}$ ), or phosphatidylinositol-3-kinase (PI3K; LY294002, $5 \mu \mathrm{M}$ ) $1 \mathrm{~h}$ prior to exposure to recombinant mouse galectin-9 for $24 \mathrm{~h}$ on day 7 of culture $(1-5 \mu \mathrm{g} / \mathrm{mL}, \mathrm{R} \& \mathrm{D}$ Systems). All inhibitors were purchased from Cell Signaling Technology.

Enrichment of Splenic cDC

Splenic cDC were enriched by staining splenocytes with CD11c-APC, followed by positive selection using APC-microbeads (Miltenyi Biotec). Enrichment was generally 40-50\%. Enriched $\mathrm{CD} 11 \mathrm{c}^{+}$cells were exposed to recombinant mouse galectin- $9(5 \mu \mathrm{g} / \mathrm{mL})$ in the presence or absence of GM-CSF $(10 \mathrm{ng} / \mathrm{mL})$ for $24 \mathrm{~h}$.
610

J Innate Immun 2017;9:609-620 DOI: $10.1159 / 000479817$ de Kivit et al. 
Flow Cytometry

To assess ALDH activity, DC were incubated with ALDEFLUOR reagent for $40 \mathrm{~min}$ at $37^{\circ} \mathrm{C}$ (StemCell Technologies) according to the manufacturer's protocol. DC incubated with the ALDH inhibitor diethylaminobenzaldehyde (DEAB) served as negative controls. Subsequent antibody stains were performed in ALDEFLUOR assay buffer. MoDC were stained using CD11b-PE/Cy7 (clone ICRF44), CD11c-PerCP/Cy5.5 (N418), CD11c-PerCP eFluor 710 (clone 3.9), CD14-PerCP/Cy5.5 (61D3), CD14-APC (clone 61D3), CD80-FITC (clone 2D10.4), CD86-PE/Cy7 (clone IT2.2), CD103-APC(B-Ly7), DC-SIGN-PE (clone eB-h209), HLADR-PE (clone LN3), TIM-3-APC (clone F38-2E2) (all eBioscience), and DC-SIGN-FITC(120507) (R\&D Systems). Murine cells were stained with CD11b-PerCP/Cy5.5 or CD11b-AlexaFluor700 (clone M1/70), B220-BV421 (clone RA3-6B2), I-A/I-E-APCeFluor780 (clone M5/114.15.2), TIM-3-APC (clone8B.2C12) (eBioscience), CD8a-PE/Cy7 (clone53-6.7), CD11c-PE/Cy7 or CD11c-APC (clone HL3, BD Biosciences), I-A/I-E-AlexaFluor647 (clone M5/114.15.2), F4/80-APC/Cy7 (clone BM8) (BioLegend) and CD103-PE (clone 2E7, Miltenyi). Expression was compared with their respective isotype control (eBioscience). Cell viability was assessed using LIVE/DEAD ${ }^{\mathrm{TM}}$ fixable near-IR dead cell stain (Life Technologies) or fixable viability dye eFluor780 (eBioscience). Flow cytometric analysis was performed using a FACSCantoII or BD Fortessa (BD Biosciences), and FlowJo software.

Quantitative PCR

qPCR analysis was performed as previously described [8]. Gene expression levels were normalized to $r p s 13$. Primers were commercially purchased (Qiagen).

\section{ELISA}

IL-10 (eBioscience), TGF- $\beta$, and TSLP (R\&D Systems) concentrations in cell culture supernatants were determined by ELISA according to the manufacturer's protocol. Galectin-9 concentrations were determined as previously described [8]. Optical density was measured using the iMark microplate absorbance reader (Bio$\mathrm{Rad})$.

\section{Statistics}

Data were analyzed using GraphPad Prism software with the unpaired Student $t$ test or one-way ANOVA followed by the Bonferroni or Dunnett post hoc test as indicated in the figure legends. $p<0.05$ was considered statistically significant.

\section{Results}

\section{Galectin-9 Induces ALDH Activity in moDC}

First, it was investigated whether galectin-9 induces $\mathrm{CD}_{103}{ }^{+} \mathrm{DC}$, which are known for their high ALDH activity. Therefore, human moDC were conditioned in vitro with recombinant galectin-9, and the expression of CD103 and ALDH activity was assessed. Galectin-9-conditioned moDC did not show an altered phenotype based on the expression of CD11c, CD11b, DC-SIGN, and HLA-DR (online suppl. Fig. 1; for all online suppl.

Galectin-9 Increases ALDH Activity in DC material, see www.karger.com/doi/10.1159/000479817), and showed a reduced expression of the costimulatory molecules CD80 and CD86 as shown previously (data not shown) [16]. Galectin-9 did not affect moDC viability (data not shown). MoDC stimulated with galectin-9 did not show increased CD103 expression and showed a slight downregulation of TIM-3 (Fig. 1a). Although moDC exposed to galectin-9 showed enhanced ALDH activity, they did not express CD103 (Fig. 1b).

\section{IEC Apically Exposed to CPG DNA and GF Enhance ALDH Activity in moDC in a Galectin-9-Dependent Manner}

IEC were shown to drive the differentiation of $\mathrm{CD} 103^{+}$ DC in a TSLP-, TGF- $\beta$-, and retinoic acid-dependent manner [17]. Therefore, we first evaluated whether IEC express galectin-9, TSLP, and TGF- $\beta$ upon apical exposure to CpG DNA in the absence or presence of GF. Only the combination of CpG DNA with GF resulted in significant mRNA expression of galectin- 9 and TGF- $\beta$ by TNF- $\alpha$ /IFN- $\gamma$-primed HT-29 cells. Although galectin- 9 secretion by HT-29 cells was increased upon apical exposure to $\mathrm{CpG}$ DNA in the presence of GF, TGF- $\beta$ release by HT-29 cells in the basolateral compartment was increased upon apical exposure to CpG DNA, but was not enhanced by GF (Fig. 2a). Neither mRNA expression of TSLP and anti-inflammatory IL-10 by HT-29 cells nor the secretion of TSLP and IL-10 in basolateral IEC-conditioned media derived from TNF- $\alpha / \mathrm{IFN}-\gamma$-primed HT29 cells apically exposed to CpG DNA and GF was detected (data not shown).

Next, it was investigated whether galectin-9 derived from IEC is involved in the induction of ALDH activity in DC in vitro. In these experiments, polarized T84 cell monolayers were used, since confluent T84 cell monolayers more closely resemble the physiology of the intestinal epithelium as T84 cells have high epithelial barrier integrity. In addition, unlike Caco- 2 cells, T84 cell monolayers respond to CpG DNA comparable to unpolarized HT-29 monolayers [14]. T84 cells were basolaterally primed with TNF- $\alpha$ and IFN- $\gamma$, and subsequently exposed apically to CpG DNA and GF. MoDC were then generated in T84 cell-conditioned medium. Analysis of the moDC revealed that this medium did not induce the expression of CD103 by moDC (Fig. 2b), but that ALDH activity in these moDC was increased (Fig. 2c). Upon neutralization of galectin-9 in the conditioned medium using a TIM-3-Fc fusion protein, conditioned medium from T84 cells exposed to CpG DNA and GF did not increase ALDH activity in moDC (Fig. 2c).

J Innate Immun 2017;9:609-620 611 


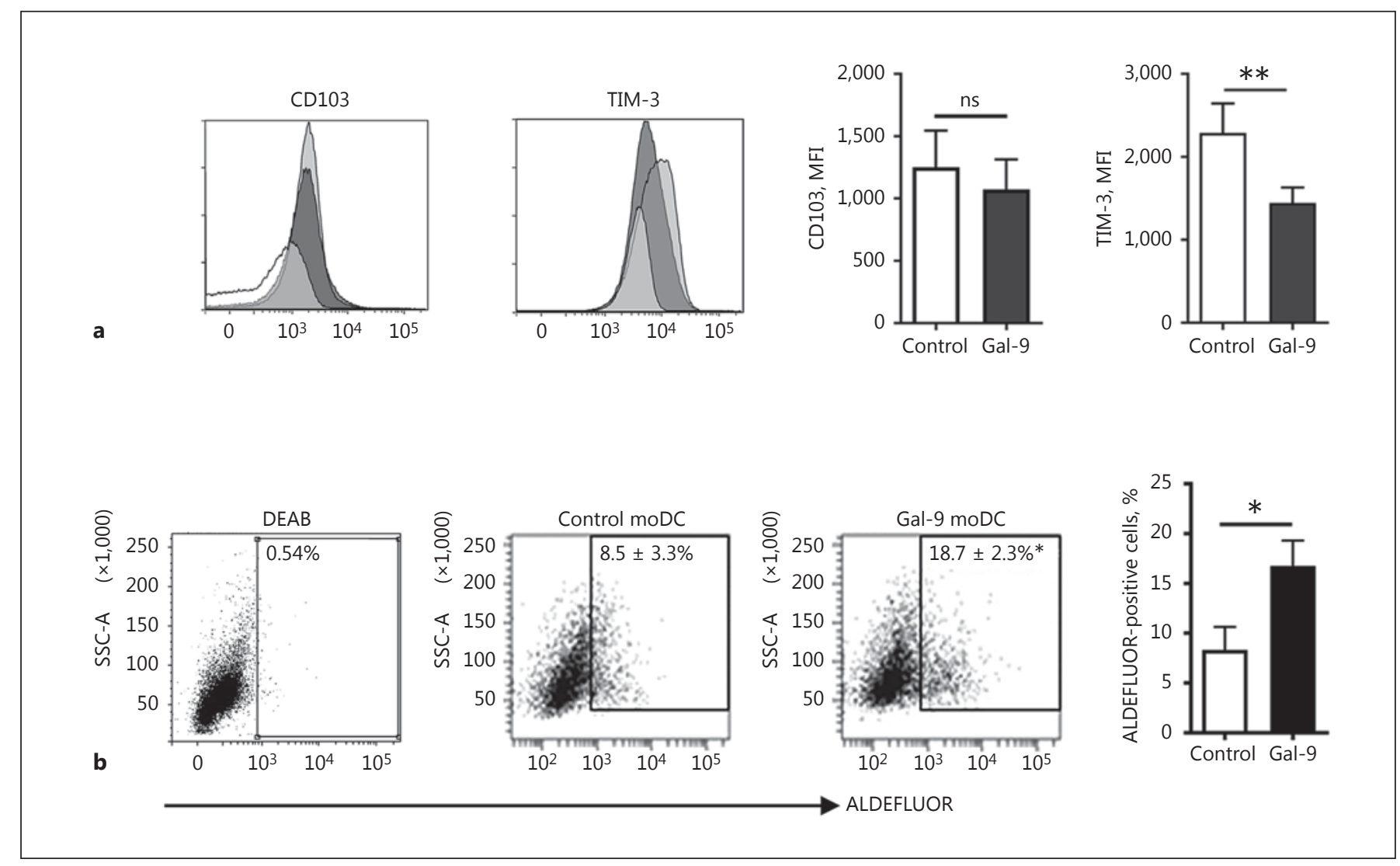

Fig. 1. Galectin-9 (Gal-9) induces ALDH activity in moDC. MoDC were exposed to recombinant Gal-9 and the moDC phenotype was evaluated. ALDH activity was assessed using the ALDEFLUOR assay. Gal-9 did not induce the expression of CD103 by moDC. MoDC expressed TIM-3, which was downregulated upon culture in the presence of Gal-9 (a). Gal-9-conditioned moDC showed in- creased ALDH activity. The percentage of ALDEFLUOR-positive moDC in DEAB controls was subtracted (b). Data represent 4 different donors, mean \pm SEM. ${ }^{*} p<0.05,{ }^{* *} p<0.01$ (Student $t$ test). Transparent, isotype control; light grey, medium control; dark grey, Gal-9 exposed moDC. ns, not significant.
GM-CSF Is Crucial for ALDH Activity in BMDC and Is Potentiated by Galectin-9

Intestinal $\mathrm{CD}_{103^{+}} \mathrm{DC}$ do not develop from bloodderived monocytes but from DC-committed precursors in the bone marrow $[5,18]$. Therefore, GM-BMDC and FL-BMDC were cultured and stimulated with recombinant galectin-9. DC were characterized as $\mathrm{CD} 11 \mathrm{c}^{+} \mathrm{F} 4 / 80^{-}$ cells, and the expression of CD11c, CD11b, I-A/I-E, and B220 was addressed. Stimulation of GM-BMDC with galectin-9 increased I-A/I-E expression. In FL-BMDC, the expression of CD11c, CD11b, and I-A/I-E were increased, while the expression of B220 was reduced (online suppl. Fig. 2). Both GM-BMDC and FL-BMDC showed expression of TIM-3 and, like in the moDC, galectin-9 downregulated the expression of TIM-3 (Fig. 3a, b).
Upon stimulation with galectin-9, GM-BMDC, but not FL-BMDC, showed ALDH activity, and this increased upon exposure to galectin-9. ALDEFLUOR-positive BMDC, however, did not express CD103 (Fig. 4a, b). Since only GM-BMDC showed increased ALDH activity upon exposure to galectin-9, we hypothesized that GMCSF is important for the induction of ALDH activity in DC. To this end, FL-BMDC were exposed to GM-CSF in the absence or presence of galectin- 9 in parallel with cultures without GM-CSF, to allow a side-by-side comparison. Upon exposure to GM-CSF, FL-BMDC showed an increased expression of $\mathrm{CD} 103$ and started to exhibit ALDH activity. However, ALDH activity was observed mainly in CD103- cells. Galectin-9 enhanced GM-CSFinduced ALDH activity (Fig. 4c). 


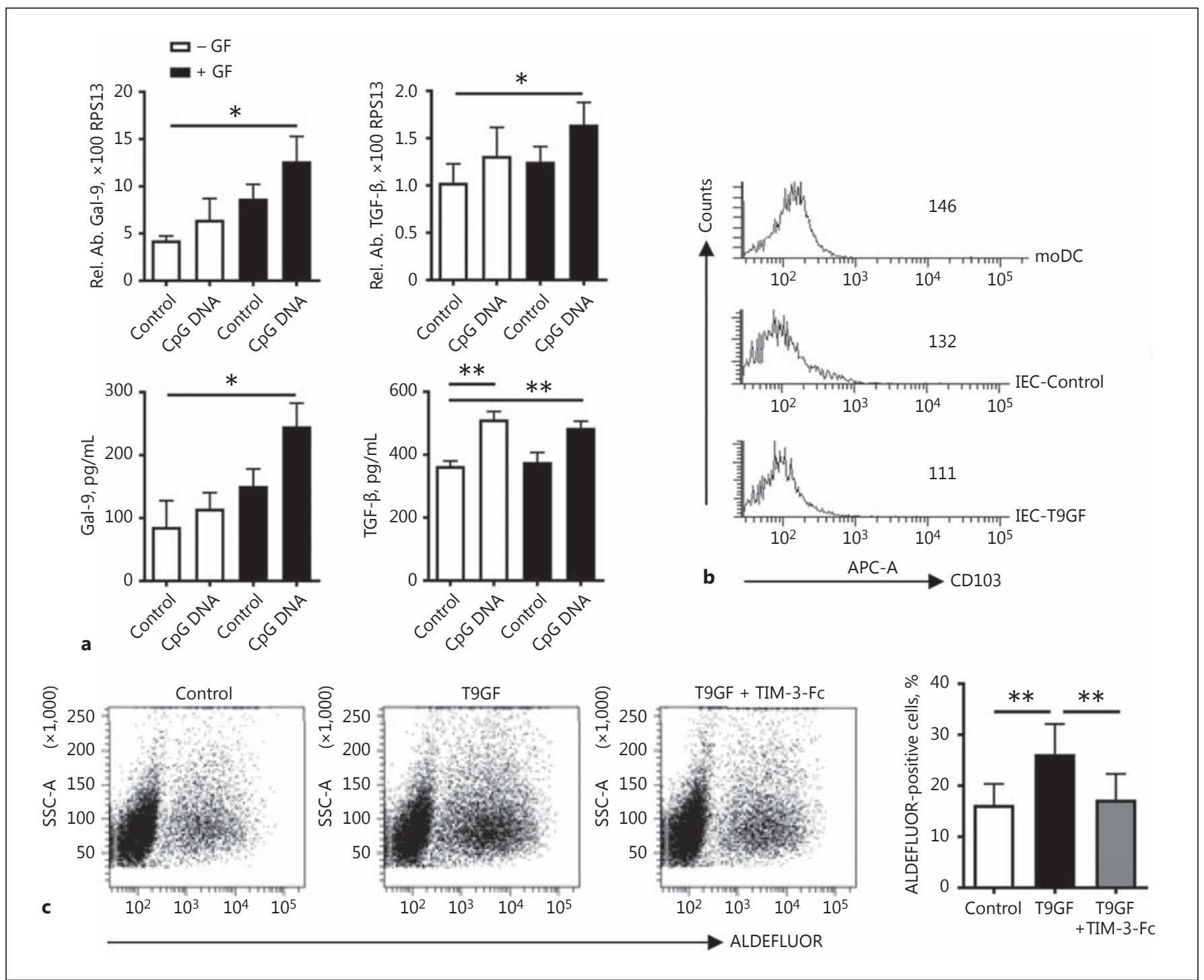

Fig. 2. Galectin-9 (Gal-9) secreted by IEC upon apical exposure to CpG DNA and GF drives ALDH activity in moDC in vitro. IEC were primed with TNF- $\alpha$ and IFN- $\gamma$ basolaterally prior to apical exposure to CpG DNA and GF. IEC showed increased Gal-9 and TGF- $\beta$ mRNA expression and secretion upon apical stimulation with CpG DNA and/or GF (a). The basolateral culture medium was then used to condition moDC. The expression of CD103 on moDC generated in T9GF-conditioned medium was not observed when compared to control medium (b), but these DC showed increased ALDH activity (c). Neutralization of Gal-9 using TIM-3Fc abrogated the induction of ALDH activity in the moDC (c). Data represent 3 different passages of IEC cultures. MoDC of 6 independent donors were generated in IEC-conditioned medium. Data are shown as mean \pm SEM. ${ }^{*} p<0.05,{ }^{* *} p<0.01$ (one-way ANOVA and Bonferroni post-hoc test). T9GF, CpG DNA and GF exposure.
Galectin-9 Enhances ALDH Activity in Splenic cDC in the Presence of GM-CSF

To evaluate whether galectin-9 could induce ALDH activity ex vivo in $\mathrm{CDC}$ as well, $\mathrm{CD} 11 \mathrm{c}^{+}$cells were enriched from wild-type spleens and stimulated with galectin-9 for $24 \mathrm{~h}$. Similar to FL-BMDC, splenic cDC did not show ALDH activity upon exposure to galectin-9 (Fig. 5a).

Galectin-9 Increases ALDH Activity in DC
In line with FL-BMDC, GM-CSF induced substantial ALDH activity in ex vivo splenic $\mathrm{CDC}$ as well, which could be further enhanced by galectin-9 (Fig. 5b). Importantly, ALDEFLUOR-positive DC did not express CD103 (Fig. 5a, b).

To further address which cDC subset exhibits ALDH activity, we evaluated ALDH activity in $\mathrm{CD} 11 \mathrm{~b}^{+} \mathrm{CD} 8 \mathrm{a}^{-}$

J Innate Immun 2017;9:609-620 DOI: $10.1159 / 000479817$ 


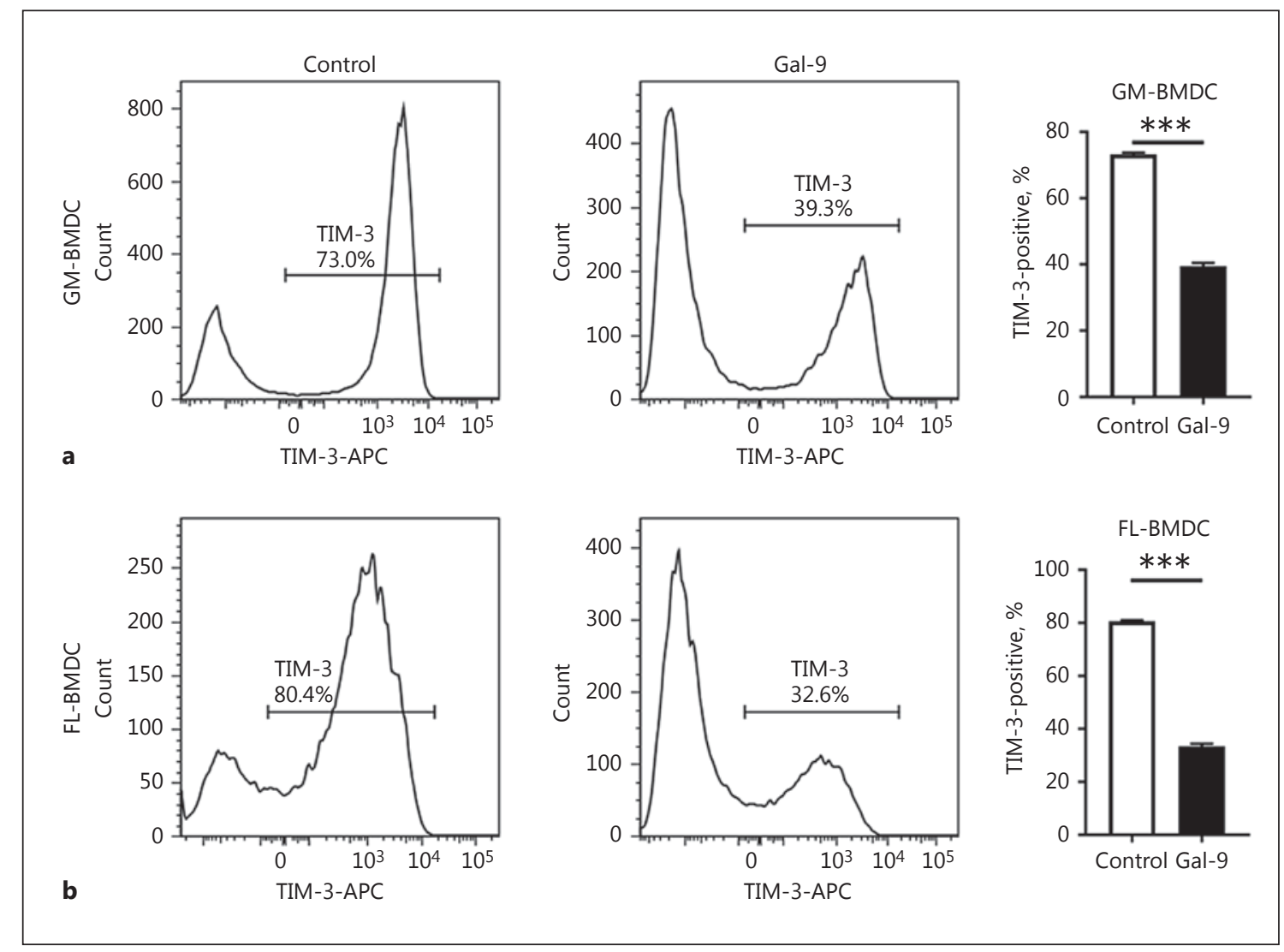

Fig. 3. Murine GM-BMDC and FL-BMDC express TIM-3. Murine BMDC were generated by culturing bone marrow cells in the presence of GM-CSF or Flt3L for 7 days. GM-BMDC and FL-BMDC were subsequently activated with galectin-9 (Gal-9) for $24 \mathrm{~h}$ and the expression of TIM-3 was assessed. Both GM-BMDC (a) and FLBMDC (b) showed expression of TIM-3, which was downregulated upon exposure to Gal-9 (a). Data represent 3 independent BMDC cultures. Data are shown as mean \pm SEM. ${ }^{* * *} p<0.001$ (Student $t$ test).

and $\mathrm{CD} 11 \mathrm{~b}^{\text {low }} \mathrm{CD} 8 \mathrm{a}^{+}$splenic cDC. Exposure of splenic cDC cultures to galectin-9, GM-CSF, or a combination of both, did not affect the frequency of $\mathrm{CD} 11 \mathrm{~b}^{+} \mathrm{CD} 8 \mathrm{a}^{-}$and $\mathrm{CD} 11 b^{\text {low }} \mathrm{CD} 8 \mathrm{a}^{+} \mathrm{cDC}$ (online suppl. Fig. 3). Upon exposure of splenocyte cultures enriched for $\mathrm{CD} 11 \mathrm{c}^{+}$cells to galectin-9 in the presence of GM-CSF, only the $\mathrm{CD} 11 b^{\text {low }} \mathrm{CD}^{2} \mathrm{a}^{+} \mathrm{cDC}$ showed high $\mathrm{ALDH}$ activity (Fig. 5c).

\section{Induction of ALDH Activity in DC Depends on p38 and PI3K Signaling}

To explore the mechanism by which galectin-9 induces ALDH activity in DC, we exposed GM-BMDC to selective inhibitors for the p38 (SB203580), JNK (SP600125), ERK1/2 (U0126), and PI3K (LY294002) signal transduction pathways $1 \mathrm{~h}$ prior to stimulation with recombinant galectin-9. Chemical inhibition of the p38 and PI3K sig- naling proteins, but not JNK or ERK1/2, prevented the induction of ALDH activity in BMDC by galectin-9 (Fig. 6).

\section{Discussion}

DC present in the intestinal mucosa play a crucial role in maintaining immunological homeostasis. Despite a high load of antigens present in the intestinal lumen, limited or no inflammatory response is elicited. It is wellestablished that intestinal $\mathrm{CD}_{103^{+}} \mathrm{DC}$ are important for the induction of tolerance through induction of $\mathrm{T}_{\text {reg }}$ cells. In particular, these $\mathrm{CD}_{103^{+}} \mathrm{DC}$ show higher mRNA expression of Aldh1a2, an enzyme that converts retinal into retinoic acid, which is important for the induction of $\mathrm{T}_{\text {reg }}$ in the gut $[1,19]$. IEC are in close contact with intes- 

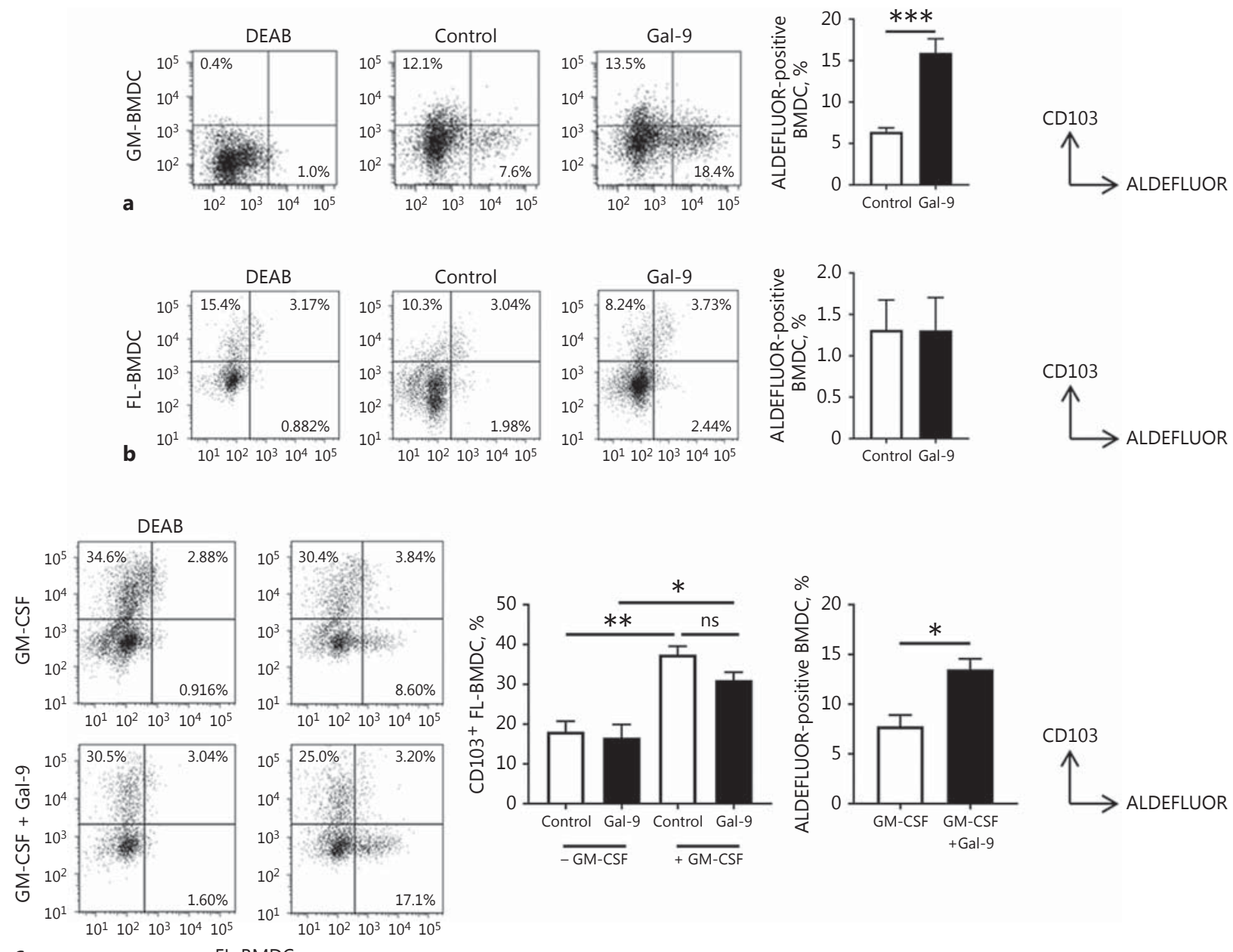

ALDEFLUOR

C

FL-BMDC

Fig. 4. GM-CSF is important for the induction of ALDH activity in BMDC, which is potentiated by galectin-9 (Gal-9), GM-BMDC or FL-BMDC were incubated with Gal-9 for $24 \mathrm{~h}$. ALDH activity was assessed by the ALDEFLUOR assay. Gal-9 induced ALDH activity in GM-BMDC (a) but not in FL-BMDC (b). However, GMCSF induced ALDH activity in FL-BMDC, which was enhanced by
Gal-9 (c). Though GM-CSF increased the expression of CD103 on FL-BMDC, ALDEFLUOR-positive DC did not express CD103 (c). Data represent 3 animals in 3 independent cultures, mean \pm SEM. ${ }^{*} p<0.05,{ }^{* *} p<0.01,{ }^{* * *} p<0.001$ (paired Student $t$ test [ALDEFLUOR] or one-way ANOVA, followed by Bonferroni post hoc test [CD103]). tinal DC and promote the differentiation of $\mathrm{CD} 103^{+} \mathrm{DC}$ $[2,17,20]$. In IBD, IEC do not promote the differentiation of tolerogenic DC, and, consequently, a reduction in ALDH-positive DC is observed in the lamina propria [21]. It has been demonstrated that the gut microbiota may play an important role in the recruitment of $\mathrm{CD} 103^{+}$ DC towards the intestinal epithelium via TLR-dependent mechanisms [22] but, to our knowledge, it is not known whether epithelial TLR activation also regulates the differentiation of $\mathrm{CD}_{103^{+}}$DC. Hence, IEC actively contrib-

Galectin-9 Increases ALDH Activity in DC ute to maintaining intestinal tolerance, and in this study, we show a novel mechanism by which galectin- 9 derived from IEC supports the induction of ALDH activity in DC.

Galectin-9 is an epithelium-derived mediator involved in supporting Th 1 and $\mathrm{T}_{\text {reg }}$ responses $[6,8]$. There is controversy amongst studies describing the role of galectin- 9 in innate and adaptive immunity. The most accepted role of galectin-9 is the induction of apoptosis of Th1 cells through interaction with TIM-3 [23]. In contrast, galectin- 9 has been associated with the induction of Th1 and 

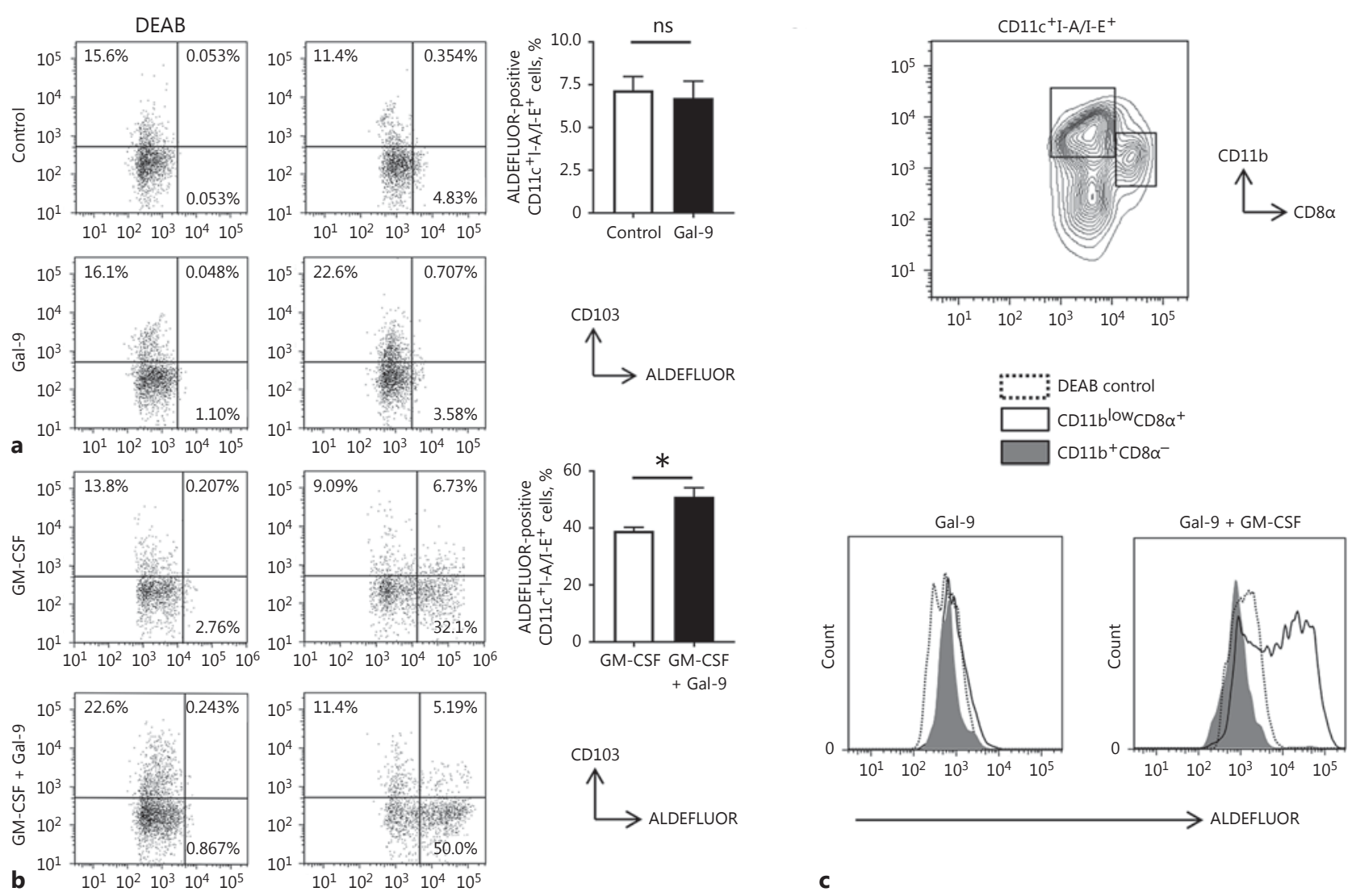

Fig. 5. Galectin-9 (Gal-9) enhances ALDH activity in splenic cDC in the presence of GM-CSF. Splenic CD $11 c^{+}$cells were enriched from wild-type spleen and stimulated ex vivo with Gal-9 in the absence or presence of GM-CSF for $24 \mathrm{~h}$. In the absence of GM-CSF, CD11 ${ }^{+} \mathrm{I}-\mathrm{A} / \mathrm{I}^{-E^{+}}$cells did not show ALDH activity either with/ without stimulation with Gal-9 (a). GM-CSF induced significant $\mathrm{ALDH}$ activity in $\mathrm{CD} 11 \mathrm{c}^{+} \mathrm{I}-\mathrm{A} / \mathrm{I}-\mathrm{E}^{+}$cells, which was enhanced by

Gal-9 (b). Further flow cytometric analysis revealed that $\mathrm{CD}_{11} \mathrm{~b}^{\text {low }} \mathrm{CD} 8 \mathrm{a}^{+}$(but not $\mathrm{CD} 11 \mathrm{~b}^{+} \mathrm{CD} 8 \mathrm{a}^{-}$) $\mathrm{cDC}$ exhibit high ALDH activity upon exposure to GM-CSF and Gal-9. The DEAB control represents bulk CD11 $\mathrm{c}^{+} \mathrm{I}-\mathrm{A} / \mathrm{I}-\mathrm{E}^{+}$cells (c). Data represent separate spleen cultures of 3-5 animals and are generated in 2 independent experiments, mean \pm SEM. ${ }^{*} p<0.05$ (Student $t$ test). ns, not significant.

$\mathrm{T}_{\text {reg }}$ responses as well, and it may exert effects independently of TIM-3 [10, 11, 13, 24, 25]. Both GM-BMDC and FL-BMDC showed high TIM-3 expression. Incubation with galectin-9 decreased the expression of TIM-3. This downmodulation of the TIM-3 receptor upon ligation of galectin-9 has been observed on NK cells as well [26]. In this study, we also showed that galectin-9 induces ALDH activity in moDC in vitro. However, further research is necessary to evaluate whether the induction of ALDH activity in DC via galectin-9 is TIM3-dependent. However, no expression of CD103 by ALDH-positive DC was observed. Recently, it was shown that CD103- DC with ALDH activity can also migrate towards the MLN and

contribute to $\mathrm{T}_{\text {reg, }}, \mathrm{Th} 1$, and $\mathrm{Th} 17$ polarization $[27,28]$. In addition, previous reports indicate the importance of retinoic acid and ALDH activity in DC in $\mathrm{T}_{\text {reg }}$ differentiation and the induction of gut homing factors on T cells [29]. Galectin- 9 can induce both Th1 and $\mathrm{T}_{\text {reg }}$ polarization in vitro $[8,12]$, and it remains to be evaluated whether DC stimulated by galectin- 9 can induce the expression of guthoming factors on T cells as well.

IEC provide a barrier between the intestinal lumen and the lamina propria. They also produce retinoic acid, TSLP, and TGF- $\beta$ to promote the differentiation of tolerogenic $\mathrm{DC}$ and $\mathrm{T}_{\text {reg }}$ differentiation $[2,16]$. IEC are constantly in contact with the microbiota, and microbi- 




Fig. 6. Galectin-9 (Gal-9) induces ALDH activity in BMDC in a p38- and PI3K-dependent manner. GM-BMDC were incubated with selective inhibitors for p38 (SB203580), JNK (SP600125), ERK1/2 (U0126), or PI3K (LY294002) $1 \mathrm{~h}$ prior to stimulation with Gal-9 for $24 \mathrm{~h}$. Gal-9 induced ALDH activity in GM-BMDC, but selective inhibition of $\mathrm{p} 38$ or PI3K prevented the induction of

ota-derived signals regulate mucosal immune responses in the intestine [30]. Under inflammatory conditions, IEC have been shown to increase their surface expression of Toll-like receptors (TLR), including TLR9 [14, 31-33]. In particular, apical TLR9 activation on IEC is important to maintain intestinal homeostasis, and CpGrich DNA from commensal bacteria can induce tolerance in the intestinal mucosa via the activation of TLR9

Galectin-9 Increases ALDH Activity in DC
ALDH activity by Gal-9 (a, b). Further analysis shows that ALDEFLUOR-positive DC did not express CD103 (a). Data represent 3 independent BMDC cultures, mean \pm SEM. ${ }^{\# \# \#} p<0.001$ compared to medium control (Student $t$ test); ${ }^{* *} p<0.01$, ${ }^{* * *} p<0.001$ (oneway ANOVA and Dunnett post hoc test with Gal-9+ DMSO serving as the control group).

$[7,34]$. Though exposure of Caco-2 cells to gut-derived commensals induced TSLP secretion [35], we did not observe TSLP expression or secretion by HT-29 or T84 cells upon apical exposure to CpG DNA. However, TGF- $\beta$ as well as galectin-9 expression by IEC was increased upon apical exposure to CpG DNA and GF. Induction of ALDH enzymes by DC was previously shown to require retinoic acid [36] whereas DC primed by ret-

J Innate Immun 2017;9:609-620 617 
inoic acid induce Foxp3 ${ }^{+} \mathrm{T}_{\text {reg }}$ cells in the presence of bystander TGF- $\beta$ [37]. Since TGF- $\beta$ is, amongst others, produced by IEC that are in close proximity to mucosal $\mathrm{CD}_{103^{+}} \mathrm{DC}$, IEC are important regulators of DC function. We observed that the neutralization of galectin-9 in IEC-conditioned medium completely blocked ALDH activity in DC. Our data therefore suggest that the apical ligation of TLR9 in the presence of GF induces the expression of galectin-9, which interacts with DC to promote ALDH activity, at least in in vitro cultures. In addition, TLR9 activation both in the absence or presence of GF enhances mRNA expression and secretion of TGF- $\beta$, which may support an anti-inflammatory microenvironment important for maintaining intestinal homeostasis. Further investigation in vivo is needed to unravel a potential role for epithelial TLR9 expression and galectin- 9 in increasing ALDH activity by DC in the gut mucosa.

Since moDC showed high ALDH activity upon culture in IEC-conditioned medium, we questioned whether this observation was due to the fact that mucosal DC in the intestine are derived from specific DC precursors present in the bone marrow instead of infiltrating monocytes. In mice, $\mathrm{CD} 11 \mathrm{~b}^{+} \mathrm{CD} 103^{+}$lamina propria DC originate from pre-DC precursors, while the $\mathrm{CD} 11 \mathrm{~b}^{+} \mathrm{CD} 103^{-}$ cell population in the gut mucosa is composed of a mixed population of monocyte-derived macrophages and DC derived from Flt3L-dependent DC-committed precursors $[5,18]$. We therefore also assessed the effects of galectin-9 on ALDH activity and the expression of CD103 in BMDC cultures. GM-BMDC showed ALDH activity, but FL-BMDC showed ALDH activity only upon exposure to GM-CSF. Similarly, splenic cDC, in particular $\mathrm{CD} 11 b^{\text {low }} \mathrm{CD} 8 a^{+}$(but not $\mathrm{CD} 11 \mathrm{~b}^{+} \mathrm{CD} 8 \mathrm{a}^{-}$) cDC, exhibited high ALDH activity upon exposure to GM-CSF and galectin-9. As it was previously shown that $\mathrm{CD} 8 \mathrm{a}^{+}$splenic DC show higher expression of TIM-3 than CD $8 \alpha^{-}$DC, this may explain our observation of $\mathrm{CD} 11^{\text {low }} \mathrm{CD} 8 \alpha^{+} \mathrm{DC}$, in particular, responding to galectin-9 [38]. Although GM-CSF was previously shown to be important to induce ALDH activity in DC and drive $T_{\text {reg }}$ polarization and expression of gut-homing factors on T cells via DC [39], we showed that galectin-9 further increases ALDH activity in DC. IEC are a major source of GM-CSF, and GM-CSF production by nonhematopoietic cells in the gut is important for the maintenance of intestinal homeostasis $[40,41]$. Moreover, stromal cells in the intestinal lamina propria have been shown to produce GMCSF, which is required for ALDH expression in mucosal DC [42]. Although we and others have observed that
GM-CSF results in the increased expression of CD103 by DC generated from bone marrow DC precursors [43], we found that the DC that exhibit ALDH activity upon stimulation with galectin-9 and GM-CSF were CD103cDC.

Not much is known about the role of galectin-9 on DC function. Though galectin- 9 can induce the maturation of monocyte-derived DC via $\mathrm{p} 38$ and ERK1/2 phosphorylation [12], we observed that both p38 and PI3K (but not JNK or ERK) signaling are important in driving ALDH activity in GM-BMDC. In particular, p38 signaling in mucosal $\mathrm{CD}_{103^{+}} \mathrm{DC}$ was found to be crucial for the induction of Foxp $3^{+} \mathrm{T}_{\text {reg }}$ cells, as it is essential for optimal ALDH expression [44]. GM-CSF was found to be crucial for the induction of ALDH activity in FLBMDC and splenic cDC. GM-CSF-mediated PI3K signaling is important for DC function (review [45]). Furthermore, the activation of the PI3K/Akt/ $\beta$-catenin pathway in DC induces the expression of regulatory molecules, including IL-10 and Aldh1a2, to drive $\mathrm{T}_{\text {reg }}$ polarization, whereas the deletion of $\beta$-catenin programs DC to induce Th1/Th17 cell differentiation [46]. Moreover, in mammary epithelial cells, ALDH activity has been found to be regulated in a PI3K/Akt-dependent fashion [47]. To our knowledge, this is the first study showing a potential link between p38 and PI3K signaling induced by galectin- 9 , resulting in increased ALDH activity in DC.

In summary, IEC showed increased galectin-9 expression upon apical exposure to CpG DNA and GF in vitro, and promoted ALDH activity in moDC in a galectin-9 dependent manner. Galectin-9 promotes ALDH activity in human moDC and murine GM-BMDC. In murine FLBMDC and splenic CD $11 b^{\text {low }} \mathrm{CD} 8 a^{+} \mathrm{cDC}$, galectin-9 enhanced ALDH activity only in the presence of GM-CSF. ALDH activity in GM-BMDC induced by galectin- 9 was found to be dependent on p38 and PI3K signaling in DC. These data provide greater insight into the molecular mechanisms by which IEC-derived galectin- 9 may regulate innate immunity via the induction of ALDH activity in DC.
618

J Innate Immun 2017;9:609-620 DOI: $10.1159 / 000479817$ de Kivit et al. 


\section{References}

1 Coombes JL, Siddiqui KR, Arancibia-Carcamo CV, Hall J, Sun CM, Belkaid Y, Powrie F: A functionally specialized population of mucosal CD103+ DCs induces Foxp3+ regulatory T cells via a TGF- $\beta$ and retinoic acid-dependent mechanism. J Exp Med 2007;204: 1757-1764

2 Iliev ID, Spadoni I, Mileti E, Matteoli G, Sonzogni A, Sampietro GM, Foschi D, Caprioli F, Viale G, Rescigno M: Human intestinal epithelial cells promote the differentiation of tolerogenic dendritic cells. Gut 2009;58: 1481-1489.

3 Esterházy D, Loschko J, London M, Jove V, Oliveira TY, Mucida D: Classical dendritic cells are required for dietary antigen-mediated induction of peripheral $\mathrm{T}_{\text {reg }}$ cells and tolerance. Nat Immunol 2016;17:545-555.

4 Cerovic V, Houston SA, Scott CL, Aumeunier A, Yrlid U, Mowat AM, Milling SW: Intestinal CD103(-) dendritic cells migrate in lymph and prime effector T cells. Mucosal Immunol 2013;6:104-113.

5 Scott CL, Bain CC, Wright PB, Sichien D, Kotarsky K, Persson EK, Luda K, Guilliams M, Lambrecht BN, Agace WW, Milling SW, Mowat AM: CCR2(+)CD103(-) intestinal dendritic cells develop from DC-committed precursors and induce interleukin-17 production by T cells. Mucosal Immunol 2015;8: 329-339.

6 de Kivit S, Saeland E, Kraneveld AD, van de Kant HJ, Schouten B, van Esch BC, Knol J, Sprikkelman AB, van der Aa LB, Knippels LM, Garssen J, van Kooyk Y, Willemsen LE: Galectin-9 induced by dietary synbiotics is involved in suppression of allergic symptoms in mice and humans. Allergy 2012;67:343-352.

7 Lee J, Mo JH, Katakura K, Alkalay I, Rucker AN, Liu YT, Lee HK, Shen C, Cojocaru G, Shenouda S, Kagnoff M, Eckmann L, BenNeriah Y, Raz E: Maintenance of colonic homeostasis by distinctive apical TLR9 signalling in intestinal epithelial cells. Nat Cell Biol 2006;8:1327-1336.

8 de Kivit S, Kraneveld AD, Knippels LM, van Kooyk Y, Garssen J, Willemsen LE: Intestinal epithelium-derived galectin- 9 is involved in the immunomodulating effects of nondigestible oligosaccharides. J Innate Immun 2013;5: 625-638.

9 Katoh S, Oomizu S, Niki T, Shimizu H, Obase Y, Korenaga M, Oka M, Hirashima M: Possible regulatory role of galectin-9 on Ascaris suum-induced eosinophilic lung inflammation in mice. Int Arch Allergy Immunol 2012; 158(suppl 1):58-65.

10 Lv K, Zhang Y, Zhang M, Zhong M, Suo Q: Galectin-9 ameliorates Con A-induced hepatitis by inducing CD4(+)CD25(low/int) effector $\mathrm{T}$ cell apoptosis and increasing regulatory T cell number. PLoS One 2012;7:e48379.
11 Seki M, Oomizu S, Sakata KM, Sakata A, Arikawa T, Watanabe K, Ito K, Takeshita K, Niki T, Saita N, Nishi N, Yamauchi A, Katoh S, Matsukawa A, Kuchroo V, Hirashima M: Galectin-9 suppresses the generation of Th17, promotes the induction of regulatory $\mathrm{T}$ cells, and regulates experimental autoimmune arthritis. Clin Immunol 2008;127:78-88.

12 Dai SY, Nakagawa R, Itoh A, Murakami H, Kashio Y, Abe H, Katoh S, Kontani K, Kihara M, Zhang SL, Hata T, Nakamura T, Yamauchi A, Hirashima M: Galectin-9 induces maturation of human monocyte-derived dendritic cells. J Immunol 2005; 175:2974-2981.

13 Gooden MJ, Wiersma VR, Samplonius DF, Gerssen J, van Ginkel RJ, Nijman HW, Hirashima M, Niki T, Eggleton P, Helfrich W, Bremer E: Galectin-9 activates and expands human T-helper 1 cells. PLoS One 2013, 8:e65616.

14 de Kivit S, van Hoffen E, Korthagen N, Garssen J, Willemsen LE: Apical TLR ligation of intestinal epithelial cells drives a Th1-polarized regulatory or inflammatory type effector response in vitro. Immunobiology 2011;216: 518-527.

15 Lutz MB, Kukutsch N, Ogilvie AL, Rossner S, Koch F, Romani N, Schuler G: An advanced culture method for generating large quantities of highly pure dendritic cells from mouse bone marrow. J Immunol Methods 1999;223: 77-92.

16 de Kivit S, Kostadinova AI, Kerperien J, Morgan ME, Muruzabal VA, Hofman GA, Knippels LMJ, Kraneveld AD, Garssen J, Willemsen LEM: Dietary, nondigestible oligosaccharides and Bifidobacterium breve $\mathrm{M}-16 \mathrm{~V}$ suppress allergic inflammation in intestine via targeting dendritic cell maturation. J Leukoc Biol 2017;102:105-115.

17 Iliev ID, Mileti E, Matteoli G, Chieppa M, Rescigno M: Intestinal epithelial cells promote colitis-protective regulatory $\mathrm{T}$-cell differentiation through dendritic cell conditioning. Mucosal Immunol 2009;2:340-350.

18 Schraml BU, van Blijswijk J, Zelenay S, Whitney PG, Filby A, Acton SE, Rogers NC, Moncaut N, Carvajal JJ, Reis e Sousa C: Genetic tracing via DNGR-1 expression history defines dendritic cells as a hematopoietic lineage. Cell 2013;154:843-858.

19 Sun CM, Hall JA, Blank RB, Bouladoux N, Oukka M, Mora JR, Belkaid Y: Small intestine lamina propria dendritic cells promote de novo generation of Foxp $3 \mathrm{~T}_{\text {reg }}$ cells via retinoic acid. J Exp Med 2007;204:1775-1785.

20 Rimoldi M, Chieppa M, Salucci V, Avogadri F, Sonzogni A, Sampietro GM, Nespoli A, Viale G, Allavena P, Rescigno M: Intestinal immune homeostasis is regulated by the crosstalk between epithelial cells and dendritic cells. Nat Immunol 2005;6:507-514.
21 Magnusson MK, Brynjolfsson SF, Dige A, Uronen-Hansson H, Borjesson LG, Bengtsson JL, Gudjonsson S, Ohman L, Agnholt J, Sjovall H, Agace WW, Wick MJ: Macrophage and dendritic cell subsets in IBD: ALDH cells are reduced in colon tissue of patients with ulcerative colitis regardless of inflammation. Mucosal Immunol 2016;9:171-182.

22 Farache J, Koren I, Milo I, Gurevich I, Kim KW, Zigmond E, Furtado GC, Lira SA, Shakhar G: Luminal bacteria recruit CD103+ dendritic cells into the intestinal epithelium to sample bacterial antigens for presentation. Immunity 2013;38:581-595.

23 Zhu C, Anderson AC, Schubart A, Xiong H, Imitola J, Khoury SJ, Zheng XX, Strom TB, Kuchroo VK: The Tim-3 ligand galectin-9 negatively regulates $\mathrm{T}$ helper type 1 immunity. Nat Immunol 2005;6:1245-1252.

24 Leitner J, Rieger A, Pickl WF, Zlabinger G, Grabmeier-Pfistershammer K, Steinberger P: TIM-3 does not act as a receptor for galectin-9. PLoS Pathog 2013;9:e1003253.

25 Su EW, Bi S, Kane LP: Galectin-9 regulates T helper cell function independently of Tim-3. Glycobiology 2011;21:1258-1265.

26 Jost S, Moreno-Nieves UY, Garcia-Beltran WF, Rands K, Reardon J, Toth I, PiechockaTrocha A, Altfeld M, Addo MM: Dysregulated Tim-3 expression on natural killer cells is associated with increased galectin-9 levels in HIV-1 infection. Retrovirology 2013;10:74.

27 Guilliams M, Crozat K, Henri S, Tamoutounour S, Grenot P, Devilard E, de Bovis B, Alexopoulou L, Dalod M, Malissen B: Skindraining lymph nodes contain dermis-derived CD103(-) dendritic cells that constitutively produce retinoic acid and induce Foxp3(+) regulatory T cells. Blood 2010;115: 1958-1968.

28 Cerovic V, Houston SA, Scott CL, Aumeunier A, Yrlid U, Mowat AM, Milling SW: Intestinal CD103(-) dendritic cells migrate in lymph and prime effector T cells. Mucosal Immunol 2013;6:104-113.

29 Iwata M, Hirakiyama A, Eshima Y, Kagechika H, Kato C, Song SY: Retinoic acid imprints gut-homing specificity on $\mathrm{T}$ cells. Immunity 2004;21:527-538.

30 de Kivit S, Tobin MC, Forsyth CB, Keshavarzian A, Landay AL: Regulation of intestinal immune responses through TLR activation: implications for pro- and prebiotics. Front Immunol 2014;5:60.

31 Abreu MT, Arnold ET, Thomas LS, Gonsky R, Zhou Y, Hu B, Arditi M: TLR4 and MD-2 expression is regulated by immune-mediated signals in human intestinal epithelial cells. J Biol Chem 2002;277:20431-20437.

32 Ewaschuk JB, Backer JL, Churchill TA, Obermeier F, Krause DO, Madsen KL: Surface expression of Toll-like receptor 9 is upregulated on intestinal epithelial cells in response to pathogenic bacterial DNA. Infect Immun 2007;75:2572-2579.
Galectin-9 Increases ALDH Activity in DC
J Innate Immun 2017;9:609-620

DOI: $10.1159 / 000479817$ 
33 Singh JC, Cruickshank SM, Newton DJ, Wakenshaw L, Graham A, Lan J, Lodge JP, Felsburg PJ, Carding SR: Toll-like receptor-mediated responses of primary intestinal epithelial cells during the development of colitis. Am J Physiol Gastrointest Liver Physiol 2005; 288:G514-G524.

34 Bouladoux N, Hall JA, Grainger JR, Dos Santos LM, Kann MG, Nagarajan V, Verthelyi D, Belkaid Y: Regulatory role of suppressive motifs from commensal DNA. Mucosal Immunol 2012;5:623-634.

35 Zeuthen LH, Fink LN, Frokiaer H: Epithelial cells prime the immune response to an array of gut-derived commensals towards a tolerogenic phenotype through distinct actions of thymic stromal lymphopoietin and transforming growth factor-beta. Immunology 2008;123:197-208.

36 Molenaar R, Knippenberg M, Goverse G, Olivier BJ, de Vos AF, O’Toole T, Mebius RE: Expression of retinaldehyde dehydrogenase enzymes in mucosal dendritic cells and gutdraining lymph node stromal cells is controlled by dietary vitamin A. J Immunol 2011; 186:1934-1942.

37 Bakdash G, Vogelpoel LT, van Capel TM, Kapsenberg ML, de Jong EC: Retinoic acid primes human dendritic cells to induce guthoming, IL-10-producing regulatory T cells. Mucosal Immunol 2015;8:265-278.
38 Nakayama M, Akiba H, Takeda K, Kojima Y, Hashiguchi M, Azuma M, Yagita H, Okumura K: Tim-3 mediates phagocytosis of apoptotic cells and cross-presentation. Blood 2009; 113:3821-3830.

39 Yokota A, Takeuchi H, Maeda N, Ohoka Y, Kato C, Song SY, Iwata M: GM-CSF and IL-4 synergistically trigger dendritic cells to acquire retinoic acid-producing capacity. Int Immunol 2009;21:361-377.

40 Sennikov SV, Temchura VV, Kozlov VA, Trufakin VA: The influence of conditioned medium from mouse intestinal epithelial cells on the proliferative activity of crypt cells: role of granulocyte-macrophage colony-stimulating factor. Gastroenterology 2002;37:10481051.

41 Egea L, McAllister CS, Lakhdari O, Minev I, Shenouda S, Kagnoff MF: GM-CSF produced by nonhematopoietic cells is required for early epithelial cell proliferation and repair of injured colonic mucosa. J Immunol 2013;190: 1702-1713.

42 Vicente-Suarez I, Larange A, Reardon C, Matho M, Feau S, Chodaczek G, Park Y, Obata Y, Gold R, Wang-Zhu Y, Lena C, Zajonc DM, Schoenberger SP, Kronenberg M, Cheroutre $\mathrm{H}$ : Unique lamina propria stromal cells imprint the functional phenotype of mucosal dendritic cells. Mucosal Immunol 2015;8: 141-151.
43 Mayer CT, Ghorbani P, Nandan A, Dudek M, Arnold-Schrauf C, Hesse C, Berod L, Stüve P, Puttur F, Merad M, Sparwasser T: Selective and efficient generation of functional Batf3dependent CD103+ dendritic cells from mouse bone marrow. Blood 2014;124:30813091.

44 Huang G, Wang Y, Chi H: Control of T cell fates and immune tolerance by $\mathrm{p} 38 \mathrm{a}$ signaling in mucosal CD103+ dendritic cells. J Immunol 2013;191:650-659.

45 van de Laar L, Coffer PJ, Woltman AM: Regulation of dendritic cell development by GMCSF: molecular control and implications for immune homeostasis and therapy. Blood 2012;119:3383-3393.

46 Manoharan I, Hong Y, Suryawanshi A, Angus-Hill ML, Sun Z, Mellor AL, Munn DH, Manicassamy S: TLR2-dependent activation of $\beta$-catenin pathway in dendritic cells induces regulatory responses and attenuates autoimmune inflammation. J Immunol 2014;193: 4203-4213.

47 Korkaya H, Paulson A, Iovino F, Wicha MS: HER2 regulates the mammary stem/progenitor cell population driving tumorigenesis and invasion. Oncogene 2008;27:6120-6130. 